\title{
Removal of Methylene Blue from Aqueous Solutions by Nitrated biomass of Cicer arientinum
}

\author{
A. A. Kale ${ }^{1}$ \\ ${ }^{1}$ Post Graduate Department of Chemistry, S.M.Joshi College, Hadapsar. Dist-Pune, (Maharashtra)
}

\begin{abstract}
Investigation of removal of methylene blue by nitrated biomass of Cicer arientinum is conducted in batch conditions. The effect of different parameters such as contact time, sorbent dose, $p H$ and temperature has been studied. Adsorption kinetic modeling data were found out. The kinetics of biosorption results shows that sorption process is well explained by pseudo-second order model with determination coefficients higher than 0.99 for sorbent under all experimental conditions. The value Kp is found to be 0.652 to 2.43 for initial and final concentrations. Thermodynamic parameter via $K D, \Delta G$ has also been calculated to determine the spontaneity of the process. The low value of activation energy indicates that sorption is an activated and physical process. The Weber and Morris intraparticle diffusion model show liquid-film, mass transfer is effective sorption mechanism. Thus nitrated biomass of Cicer areintinum is a low cost and easily available efficiently used as an excellent sorbent for the removal of $\mathrm{MB}^{+}$from wastewater. It can be safely concluded that biomass of Cicer arientinum is much economical effectual, viable and can be an alternative to more costly adsorbents.
\end{abstract}

Key words: Methylene blue (MB), biosobent, adsorbent, Nitrated biomass (sorbent S-IV), Langmuir and Freundlich isotherms

\section{Introduction}

Bengal gram, pulses maize, wheat, bajara are the major crops of Maharashtra, agricultural waste from these crops are available in ample amount. Methylene blue is widely released as waste from industry and can be harmful for the environmental flora and fauna. Furthermore, in humans, it will cause stomach upset and ulcer, mental retardation, liver, and brain damage. Therefore, removal of methylene blue from effluents is essential. In general, a sorbent can be assumed as "low cost" it is requires little processing, is abundant in nature or is by product or waste material from another industry. Adsorbents with a wide variety of surface structure and pore size distribution are obtained by modifying the preparation conditions of either physical and or chemical activation processes. In both the methods there is a reaction of the precursor with the activating agent to develop the porosity. ${ }^{1-2}$ In the late 1970 chemical activation of charcoal using KOH was reported. ${ }^{5-6}$. Literature survey reveals the modified methods for the charcoal preparation by using different inorganic salts and heavy acids like sulphuric acid and nitric acid. In chemical activation process the lignocellulosic precursor is mixed with a chemical reagent for restricting the formation of tar. The process followed by carbonization and neutralization by washing, yields the activated carbon ${ }^{3-4}$ acids, alkalis, salt solutions have been used for chemical activation.

Pseudo-activated carbon prepared by treating the lignocellulosic precursor with concentrated sulphuric acid showed adsorptive and ion exchange properties ${ }^{2}$. The adsorption was found to obey Langmuir and freundich adsorption models. Literature survey also reveals that cotton seeds hulls ${ }^{1}$, peat ${ }^{7}$, walnut shell ,cherry stone, apricot stone nut, grapes seeds ${ }^{9}$, eucalypts ${ }^{10}$,olive and peach stone ${ }^{11}$, wood saw dust have been found to be suitable precursors owing to their high carbon and low ash contents. Newer adsorbent materials like tree barks, cotton capsule shells, cauliflower ${ }^{12}$ saw dust ${ }^{13}$, rice straw, ground nut husk carbon ${ }^{14}$, tea leaves ${ }^{15}$, waste wool, ${ }^{6}$ have been, investigated for removal of pollutants from waste water in the last two decades.

Growing interest has been focused for the use of phosphoric acid as an activating agent in the production of activated carbon from minerals and botanical sources ${ }^{1-2}$. Effect of temperature, $\mathrm{pH}$, and concentration of the adsorbate solution on adsorption capacity was studied on activated alumina, sorption and desorption characteristics of the methylene blue have been studied on kaolinite. The adsorption behavior of the cationic dye methylene blue on cellulose ${ }^{16}$ from its own solution and from its mixture with an anionic dye, methyl orange has been investigated. The physical and chemical surface characteristics of activated carbon and adsorption of methylene blue from waste water. Kinetics and equilibrium studies of adsorption of methylene blue on jute fiber ${ }^{17}$ carbon have also been reported. Leaves of cauliflower were used for the removal of dyes like crystal violet, malachite green, rhodamine B, and methylene blue. Equilibrium kinetic modeling of Methylene blue biosorption by pretreated streptomyces vimosus ${ }^{18}$ indicated that there is an increase in $\%$ dye adsorption with increase in temperature.Study of kinetics and mechanism of methylene blue sorption on to palm kernel fiber reveals that sorption of methylene blue on to kernel fiber follows a chemical activation mechanism. The adsorption study of azo dyes with similar structures was carried out on neutral alumina ${ }^{19}$ and the difference in adsorption of dyes has been explained on the basis of their molecular weight and structural complexity ${ }^{20}$. 
Literature available revealed that a large number of researchers are working to tap the scope of various cheaper biomaterial like crushed coconut shell, treated saw dust ${ }^{21}$ peanut hull ${ }^{22}$ baggase pith biomass, sawdust ${ }^{23}$ red onion $\operatorname{skin}^{24,}$ new pods of $\operatorname{tur}^{25}$, coir pith, fibres of wool,cotton,jute,bamboo as biosorbents. Removal abilities of various biosorbent like sorghum straw, fly ash, banana pith, charoli bark, bacteria, algae, fungi, yeast and dead biomass, have also been investigated. ${ }^{30}$ Literature survey of adsorption study indicated that up till now studies have been carried out on alumina ${ }^{27}$, silica gel polyaniline ${ }^{28}$, graphite, fuller earth ${ }^{29}$, animal charcoals etc.as adsorbents which are costlier ones.

\section{Materials and Methods}

\subsection{Sorbate and Chemicals}

The solutions of Cationic dye of amorphous nature methylene blue (3,9 bis - diamino phenathionium chloride) sorbate having molecular formula $\mathrm{C}_{16} \mathrm{H}_{18} \mathrm{~N}_{3} \mathrm{SCl}$ were prepared by dissolving appropriate amounts of dry powdered dye stuff in bidistilled water. Concentrations of the solutions used for this studies; were 0.799 mg/L., 7.99 mg/L, $39.9 \mathrm{mg} / \mathrm{L}$ and $79.99 \mathrm{mg} / \mathrm{L}$. (All Chemicals used Merck Chem.).

\subsection{Sorbent}

The stalks of Cicer arientinum were collected, cleaned and shade dried. The dried material was crushed, powdered and then taken in a beaker and soaked in AR conc. nitric acid for 2 hours, the mass was then heated on a water bath till the brown fumes ceased. It was then washed thoroughly with distilled water till the brown black mass was acid free. It was then dried at $110{ }^{\circ} \mathrm{C}$ in the oven for 3 hours. The dried material was passed through $0.63 \mathrm{~mm}$ mesh get particles of uniform size sorbent and stored in vacuum desiccators before use.

\subsection{Sorption Kinetics}

The three sets of experiments and each set include $50 \mathrm{mg}$ of sorbent was taken in different conical flasks, to each of these flasks $25 \mathrm{ml}$ of dye solution of initial concentration $(\mathrm{Co}=0.799 \mathrm{mg} / \mathrm{L})$ was added. The volume was made up to $100 \mathrm{ml}$ by adding distilled water. The flasks were protected from sunlight and stirred on magnetic stirrer with constant speed400 rpm for a period of 2,4,6,8,10,12,14,30, and 60 minutes respectively and filtered through whatmann filter paper. The absorbance of the filtrate was measured using systronic -112 photoelectric colorimeter at wavelength $640 \mathrm{~nm}$ filter. The same procedure mentioned above was used to study the effect of different variables mentioned in work. The dye uptake capacity for the adsorbate was calculated by simple concentration method. Uptake capacity was calculated from the mass balance as follows.

$$
\mathrm{q}=\frac{(\mathrm{Co}-\mathrm{Ct}) \mathrm{V}}{100 \mathrm{~W}}
$$

Where $\mathrm{q}$ is the quantity of sorbate (dye or metal) uptake by biomass, Co and Ct are the initial and final concentrations respectively. $\mathrm{V}$ is the volume of solution in $\mathrm{ml}$ and $\mathrm{W}$ is the dry weight of the biomass added. Calibration and actual experiments were carried triplicate and mean values are presented.

\subsection{Characterization of biosorbents.}

\section{Result and Discussion}

The physical parameter and I R spectrum data of nitrated biomass of Cicer arientinum for Sorbent is described in Table-1 and Table-2 respectively.

Table- 1

\begin{tabular}{|l|l|c|l|l|}
\hline Adsorbent & $\begin{array}{l}\text { Bulk } \\
\text { density g / } \\
\text { cc }\end{array}$ & $\begin{array}{l}\text { Moisture } \\
\text { content \% }\end{array}$ & $\begin{array}{l}\text { Ash } \\
\text { Content \% }\end{array}$ & $\begin{array}{l}\text { Volatile } \\
\text { material \% }\end{array}$ \\
\hline S-IV & 0.58 & 6.8 & 8.1 & 17.2 \\
\hline
\end{tabular}

Table-2

\begin{tabular}{|l|}
\hline I R spectrum data for Sorbent \\
\hline Nitrated biomass of C.arientinum: $3340 \mathrm{~cm}^{-1} \quad$ broad $-\mathrm{OH}, 2924 \mathrm{~cm}^{-1}-\mathrm{NH}, 1725 \mathrm{~cm}^{-1} \mathrm{COOH} \cdot$ \\
\hline
\end{tabular}




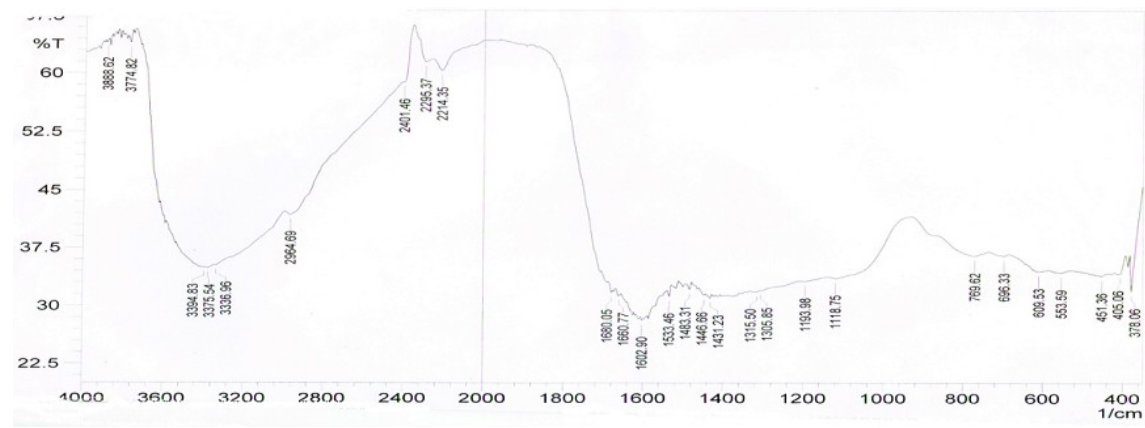

Fig.1 Infra Red Spectrum of biosorbent

\subsection{Sorption Kinetic Models}

1. Percentage removal analysis of sorption data: The removal percentage is calculated by equation $\mathrm{PR}(\%)=[1-\mathrm{Ce} / \mathrm{Co}] \times 100$

Where PR $\%=$ removal percentage of dye or metal ion from static system after agitation $\mathrm{Co}=$ of initial metal ion concentration, $\mathrm{Ct}$ with fixed dosage of adsorbent and $\mathrm{Ce}=$ sorbate concentration at experimental equilibrium stage.

\section{Langmuir isotherm model:}

Langmuir isotherm was applied for adsorption equilibrium data. The Langmuir isotherm is based on the following assumptions:

- Adsorbate / metal ions are chemically adsorbed at fixed number of well - defined sites •each site can hold only one ion. All sites are energetically equivalent; and There is no interaction between adsorbed ions. When the initial sorbate concentration increases adsorption increases whilst the binding sites are not saturated. The unmodified Langmuir equation is as follows

$\mathrm{Qe}=\mathrm{abCe} / 1+\mathrm{bCe} \quad$ Where $\mathrm{a}=$ maximum adsorption capacity $(\mathrm{mg} / \mathrm{g})$

$\mathrm{b}=$ Langmuir isotherm parameter related to the energy of adsorption $(1 / \mathrm{mg})$

3. Freundilich isotherm model: Freundlich equation is used for heterogeneous surface energy term. Freundlich isotherm can also be used to explain adsorption phenomenon as given:

$\mathrm{Qe}=\mathrm{KfCe}^{1 / \mathbf{n}}$

The linearized Freundlich model isotherm is represented by equation

$\log 10 \mathrm{qe}=\log 10 \mathrm{Kf}+1 / \mathrm{n} \log 10 \mathrm{Ce}$

Where, Kf and $\mathrm{n}$ are constants incorporating all factors affecting the adsorption capacity and an indication of the favorability of metal ion adsorption onto carbon respectively.

4. Adsorption thermodynamic equation: Value of the thermodynamic parameter free energy $\Delta \mathrm{G}^{\circ}$ were calculated using following thermodynamic equation (Sarin and Pant, 2006)

$\Delta \mathrm{G}^{\circ}=-\mathrm{RT} \ln \mathrm{K}$; where $\Delta \mathrm{G}^{\circ}$ change in free energy $(\mathrm{KJ} / \mathrm{mol}) ; \mathrm{T}=$ Absolute temperature $(\mathrm{K}), \mathrm{R}($ Universal gas constant $)=8.314 \mathrm{~J} / \mathrm{mole} . \mathrm{K} ; \mathrm{K}$ is the equilibrium constant at temperature, $\mathrm{T}$. The equilibrium constant, $\mathrm{K}$ can be calculated from. $\mathrm{K}=\mathrm{qe} / \mathrm{Ce}$

\section{Kinetic models:}

Kinetics of MB adsorption on stalks of Cicer arientinum can be modeled by the pseudo first order Lagergren equation and Pseudo second order model. The rate constant of adsorption from the first order rate expression. $\log (\mathrm{qe}-\mathrm{qt}=\log \mathrm{qe}-(\mathrm{Kt} / 2.303) \mathrm{t}$

Where qe and $\mathrm{q}$ are the amount of dye adsorbed $(\mathrm{mg} / \mathrm{g})$ at equilibrium and $\mathrm{K} 1$ is the rate constant. The secondorder kinetics model is expressed as $\mathrm{t} / \mathrm{q}=1 / \mathrm{k}_{2} \mathrm{qe}_{2}+\mathrm{t} / \mathrm{qe}$. The initial adsorption rate $(\mathrm{mg} / \mathrm{g})$ to can be defined as $\mathrm{n}=\mathrm{k}_{2} \mathrm{qe}_{2}$

The initial adsorption rate (h) equilibrium adsorption capacity (qe) and $2^{\text {nd }}$ order rate constant $\mathrm{K} 2 \mathrm{~g} / \mathrm{mg}$ $\mathrm{min}$ ) are determined experimentally, from the slope and intercept of the plot.

6. Intra particle diffusion study: Adsorption by porous particles is a process which involves a number of steps. The most common empirical function which explains adsorption is that the uptake varies almost proportionally with $\mathrm{t}^{1 / 2}$ and rather than contact time. $\mathrm{Qt}=\mathrm{k}$ id $1 / 2+\mathrm{C}$

According to the equation the plot of qt vs. $\mathrm{t}^{1 / 2}$ should be a straight line passing through origin, when the intraparticle diffusion is the rate controlling step. If the plot of $\mathrm{qt} v \mathrm{vs} . \mathrm{t}^{1 / 2}$ is non linear it indicates the adsorption is not governed by a single mechanism. 


\section{Effect Of Contact Time}

A study of effect of time on adsorption of Methylene blue on sorbent indicates that at all the concentrations of the dye rate of adsorption is quite high and the process reaches equilibrium within 30 seconds, ( Fig.2). The trend of adsorption is decreases with time, probably due to saturation of the available sites.

The plots of \% adsorbed vs. time shows two distinct regions one clearly indicating rapid adsorption and the other indicating the slowed down rate. This can be caused due to strong attractive forces between the dye molecules and the sorbent, fast diffusion onto the external surface followed by fast pore diffusion into the intra particular matrix to attain rapid equilibrium.

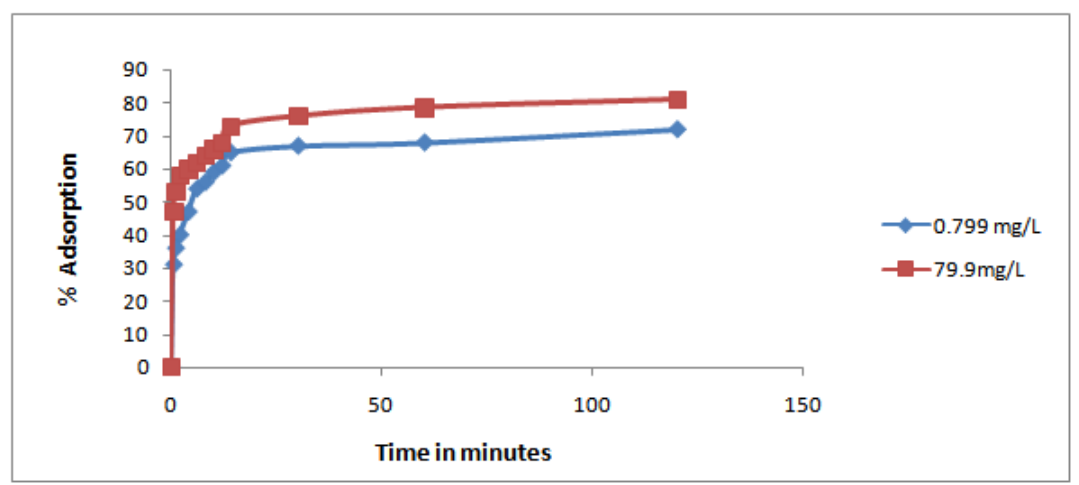

Fig-2. \% Adsorption vs. time S- IV (Co= $0.799 \mathrm{mg} / \mathrm{Ltr} . \& 79.9 \mathrm{mg} / \mathrm{Ltr}$.

\subsection{Effect of Adsorbent dose:}

Although the \%age removal increases with the adsorbent dose, the adsorption capacity shows significant decrease at equilibrilium, (Fig.3). The plot of adsorption capacity vs. time indicates that the amount of sorbent also has an effect on the contact time required to attain equilibrium. The smallest material dose (50 $\mathrm{mg}$ ) attained equilibrium after 30 seconds while the highest dose attained it after 60 seconds.
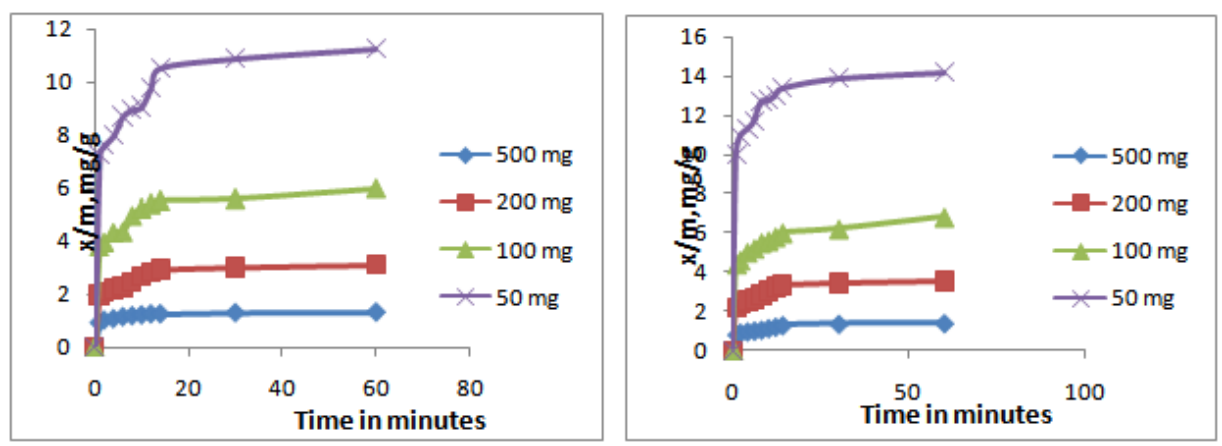

Fig.-3 Adsorption Capacity vs. time S- IV $(\mathrm{Co}=0.799 \mathrm{mg} / \mathrm{Ltr}$., $79.9 \mathrm{mg} / \mathrm{Ltr}$. $)$

\subsection{Effect of $\mathrm{pH}$ on adsorption of $[\mathrm{MB}]^{+}$by Sorbent}

The $\mathrm{pH}$ of a solution is an important factor which controls any adsorption process. The dye binding sites on the surface of the adsorbent are often modified by change in the $\mathrm{pH}$ of the solution. Similarly the chemistry and the structure of the dye molecules is also $\mathrm{pH}$ dependent .Methylene blue is cationic dye and exists as methylene blue $[\mathrm{MB}]^{+}$in solutions. Initially there is a competition for $\mathrm{H}^{+}$and $[\mathrm{MB}]^{+}$ions, to attach to the adsorption sites However as $\mathrm{pH}$ increases the number of $\mathrm{H}^{+}$ions in solution decreases till $\mathrm{pH} 4$, and a slight increase is observed in adsorption of the dye. As the $\mathrm{pH}$ increases beyond 6, it is observed that the adsorption falls and nearing the equilibrium maximum dye cations are on the surface of the sorbent. As $\mathrm{pH}$ increases the $[\mathrm{OH}]$ - and the remaining $[\mathrm{MB}]^{+}$cations appear to form pairs due to electrostatic attraction and the $[\mathrm{MB}]^{+}$ions are held back in solution. 


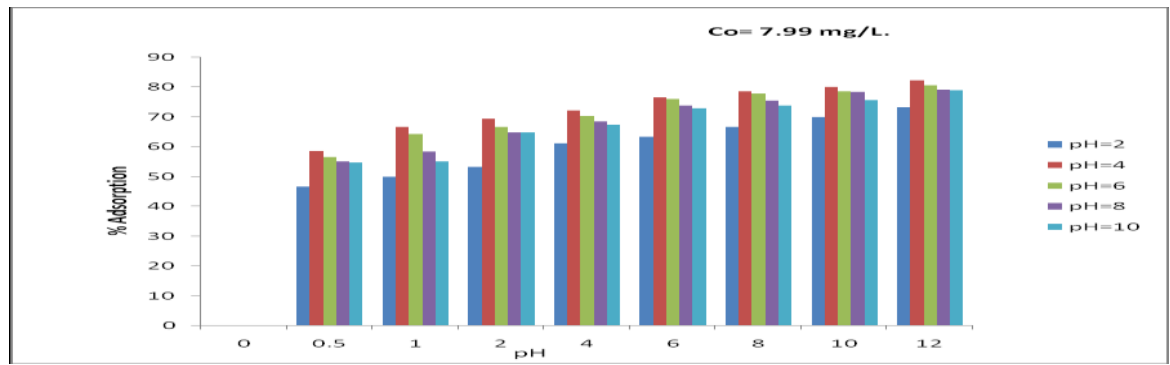

Fig-4 Effect of pH on adsorption of MB by S- IV

\subsection{Effect of Initial concentration}

Sorbent shows an increasing trend in adsorption with increase in initial concentration of the dye, for $\mathrm{Co}=0.799 \mathrm{mg} / \mathrm{Ltr}$. the $\%$ adsorption is 44 to $63 \%$ while for $\mathrm{Co}=79.9 \mathrm{mg} / \mathrm{Ltr}$. adsorption is 59 to $81 \%$,( Fig-5).

At a higher biomaterial to solute ratio a fast superficial sorption on to the sorbent surface takes place producing a lower solute concentration in the solution. A fixed mass of sorbent can sorbs only a certain amount of dye, therefore larger the sorbent mass, larger the amount of sorbate that can be removed. As the sorbent dose increases the amount of dye sorbed per unit gram of sorbent gets reduced thus causing a decrease in the adsorption capacity. The concentration of the dye at the surface of the sorbent differs from that in the solution, and therefore there exists a concentration gradient in the solution and at the surface of sorbent.

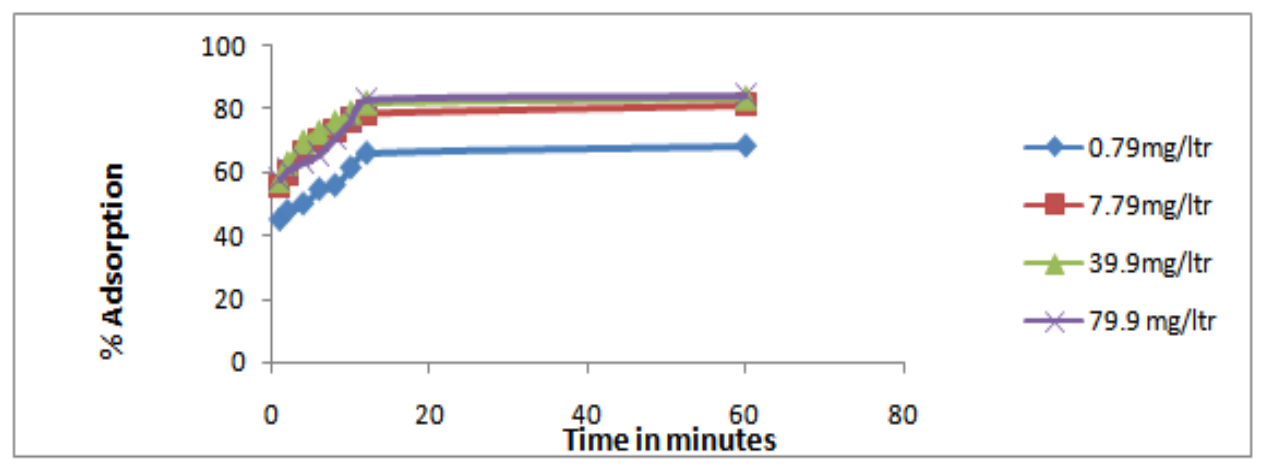

Fig. 5 Effect of initial concentration on sorption of M.B. by S-IV

\subsection{Effect of Temperature}

Effect of temperature on adsorption of $[\mathrm{MB}]^{+}$by S-IV experiments were carried out at four temperatures $15^{\circ} \mathrm{c}, 25^{\circ} \mathrm{c}, 35^{\circ} \mathrm{c}$ and $45^{\circ} \mathrm{c}$ using thermostat to maintain the temperature. The plots of \% adsorption vs. time, fig.6, using S-IV indicate that maximum amount of $[\mathrm{MB}]^{+}$are adsorbed at $45^{\circ} \mathrm{c}$ In case of S-IV the rate of adsorption is very less at $15^{\circ} \mathrm{c}$ and increases with temperature. The rates constant $\mathrm{KD}$ values at $25^{\circ} \mathrm{c}, 35^{\circ} \mathrm{c}$ and $45^{\circ} \mathrm{c}$ are the same for some values of initial concentration; (Table -3). The increase in sorption capacities with temperature indicates that with increasing temperature mobility of the $[\mathrm{MB}]^{+}$ions increases. With rise in temperature the interaction between the dye molecules and the sorbent surface become more effective, the increase in the value of $\mathrm{x} / \mathrm{m}$ with temperature also indicates the sorption process to be endothermic. The $\Delta \mathrm{G}$ values are negative indicating the spontaneity of the reactions and favorable adsorption at elevated temperatures.

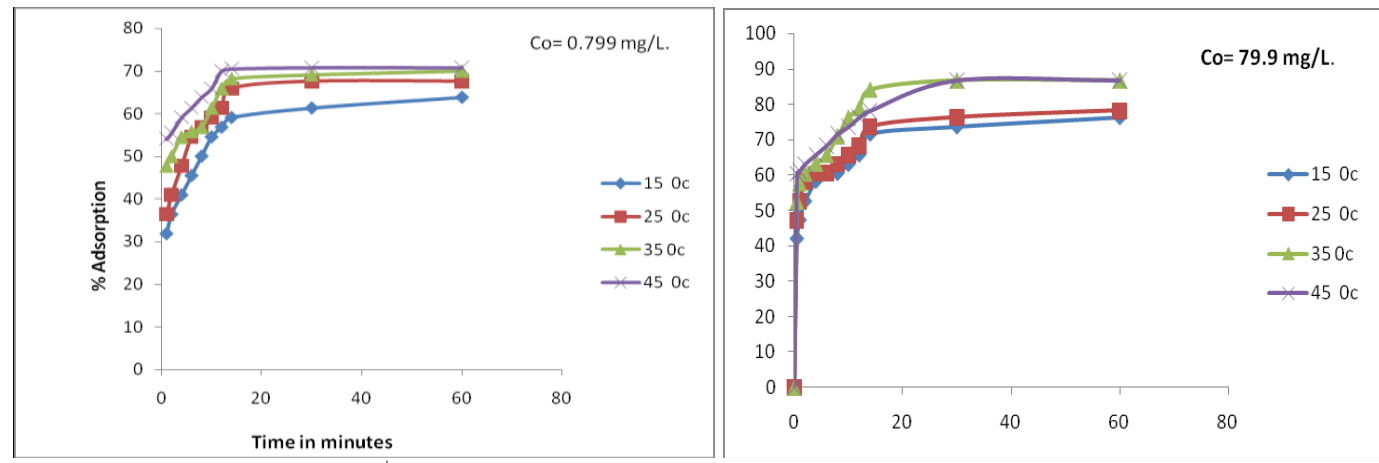

Fig.6 \%Sorption of $[\mathrm{MB}]^{+}$by by $50 \mathrm{mg} \mathrm{S-IV}$ at temperatures $\mathrm{Co}=0.799 \mathrm{mg} / \mathrm{Ltr} ., 79.99 \mathrm{mg} / \mathrm{Ltr}$. 


\section{Adsorption isotherm modeling}

The Langmuir and Freundlich model of isotherms was analyzed in the light of the data obtained on adsorption of $[\mathrm{MB}]^{+}$cation on S-IV. In this work the equilibrium data was obtained by varying the solute concentration while the biosorbent dose was kept constant under optimized physico- chemical conditions.

\subsection{Thermodynamic parameters: At $298^{\circ} \mathrm{C}$}

Effect of initial concentration and sorbent material on KD

Table-3

\begin{tabular}{|l|l|l|}
\hline \multicolumn{1}{|c|}{ Co $\mathbf{~ m g / L t r . ~}$} & KD & $\Delta \mathbf{G ~ J / m o l e / K}$ \\
\hline 0.799 & 2.133 & -1875.9 \\
\hline 7.99 & 4.32 & -3623.5 \\
\hline 39.99 & 3.71 & -3242 \\
\hline 79.99 & 3.74 & -3262.6 \\
\hline
\end{tabular}

Effect of temperature and sorbent material on $\mathrm{KD}(\mathrm{Co} \mathrm{mg} / \mathrm{L}=\mathbf{0 . 7 9 9})$

Table-4

\begin{tabular}{|l|l|l|l|l|}
\hline \multicolumn{3}{|c|}{ Co mg/Ltr. $=\mathbf{0 . 7 9 9}$ Co mg/Ltr. $=79.9$} \\
\hline Temperature & KD & $\Delta \mathbf{G ~ J / m o l e / K}$ & KD & $\Delta \mathbf{G ~ J / m o l e / K}$ \\
\hline 288 & 1.745 & -1332.46 & 3.22 & -2798.65 \\
\hline 298 & 2.133 & -1875.93 & 3.74 & -3376.17 \\
\hline 308 & 2.371 & -2209.62 & 6.59 & -4826.03 \\
\hline 318 & 2.665 & -2590.26 & 6.59 & -4982.72 \\
\hline
\end{tabular}

\subsection{Langmuir model of isotherm}

The linear plots for Ce vs. Ce/qe fig.7 for S-IV were straight lines indicating the applicability of the Langmuir adsorption isotherms. This is also indicative of the formation of monolayer coverage on the surface of the sorbent in the concentration range studied. The values of $a$ and $b$ were found to be 13.605 and 1.2088 for SIV. Hall separation factor $\mathrm{Rf}$ were evaluated for both the sorption process and were found to be less than 1 indicating favorable adsorption.

Table-5

\begin{tabular}{|l|l|l|l|}
\hline Sorbent & a & b & RL \\
\hline S-IV & 13.605 & 1.2088 & $8.5 \times 10^{-3}$ \\
\hline
\end{tabular}

The coefficient of determination was much less than 0.5 in both cases.

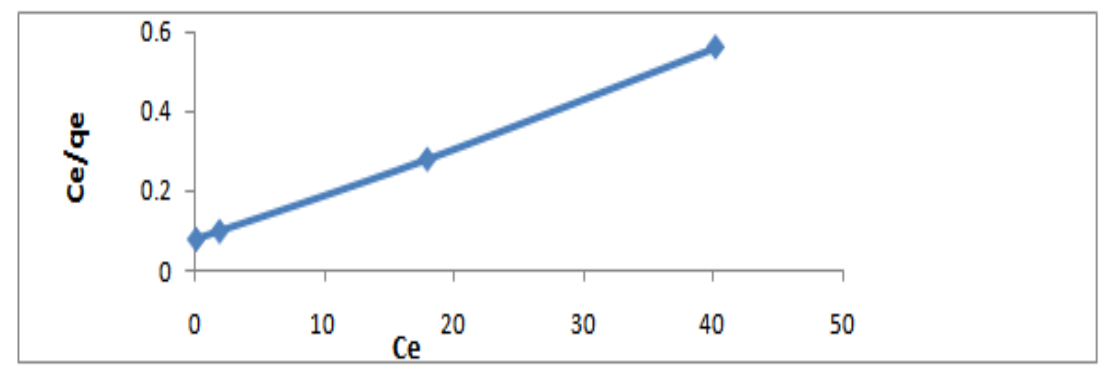

Fig .7 A Plot of Ce vs. Ce/qe for S-IV

\subsection{Freundlich model of isotherms:}

The Freundlich equation indicates the adsorption capacity or the loading factor on the adsorbent which is a function of the equilibrium concentrations of the solutions The equilibrium established between the adsorbed dye molecules and those remaining unadsorbed in solutions is represented by the Freundlich isotherm (Sag and Kutsac 1995 and references therein.) The Freundlich isotherm coefficient for the adsorption capacity $\mathrm{Kf}$ and intensity of adsorption $(1 / \mathrm{n})$ have been evaluated from fitting of the data given in the table 6 . Kf gives an idea about the rate of adsorbate removal while $1 / \mathrm{n}$ gives an indication of the sorbate -sorbent bonds. The value of Kf up to 727.05 and minimum up to $1.86 \times 10^{-5}$ have been reported $\mathrm{n}$ values up to a minimum of 0.588 have also been reported by Babu and Ramakrishna (2001). 
Removal of Methylene Blue from Aqueous Solutions by Nitrated biomass of Cicer arientinum.

Table-6 Kf and $\mathrm{n}$ for adsorption on S-IV

\begin{tabular}{|l|l|l|l|}
\hline Temperature & Kf & $\mathbf{n}$ & $\mathbf{R}^{\mathbf{2}}$ \\
\hline 298 & 5.08 & 0.8939 & 0.983 \\
\hline 308 & 5.97 & 0.8942 & 0.988 \\
\hline 318 & 7.778 & 0.819 & 0.9922 \\
\hline 328 & 8.630 & 0.6548 & 0.9702 \\
\hline
\end{tabular}

The coefficients of determination are much better than those obtained from the Langmuir model. This indicates that the Freundlich is a better model to explain the adsorption dye by S-IV

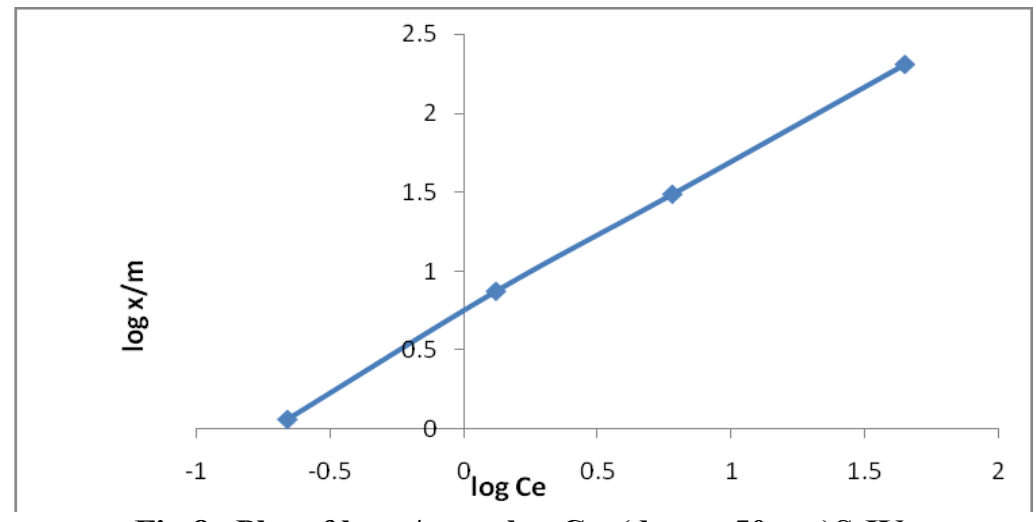

Fig.8 Plot of $\log \mathrm{x} / \mathrm{m}$ vs. $\log$ Ce. $($ dose $=50 \mathrm{mg}) \mathrm{S}-\mathrm{IV}$

\section{Kinetic study}

The majority research on dye adsorption systems revealed that two mechanism controlled dye adsorption 1) external 2) Internal diffusion. Some of the kinetic models used to assess the order of reaction are: 1) Pseudo-first order kinetic model by Lagergren, this is based on solid capacity 2) Pseudo second order kinetic model by Ho's and McKay is based on solid phase adsorption and external diffusion 3) Intraparticle diffusion model of Weber Morris. In order to describe the adsorption kinetics using S-IV as adsorbents for removal of $[\mathrm{MB}]^{+}$. Initial concentrations $0.799,7.9939 .9$ and $79.99 \mathrm{mg} / \mathrm{Ltr}$. were used. The pseudo first order model was applied. The plots of $\log$ (qe-qt) Vs t for all values of Co are shown in fig-9. The plots are expected to yield the straight lines if this model is applicable. Since straight lines are not obtained, the values of slopes are negative and $\mathrm{R}^{2}$ values also vary between 0.994 and 0.99 it has been concluded that this model is not applicable.

Modeling has been done using the pseudo second order equation developed by Ho and Mackay. The plots of $\mathrm{t} / \mathrm{qt}$ vs. $\mathrm{t}$ yield straight lines indicating that the sorption process follows the pseudo second order kinetics. The values of rate constants $\mathrm{K}_{2}$ were found to be $0.178,0.12(\mathrm{~g} / \mathrm{mg} / \mathrm{min})$ for initial dye concentration 0.799 , and $79.9 \mathrm{mg} /$ Ltr. respectively, (Table-7). The decrease in the values of $\mathrm{K}_{2}$ for various initial concentrations is quite significant. The values of equilibrium sorption capacity obtained from the plot were found to vary from the experimental values, indicating non ideal adsorption and that removal off the dye involved number of processes such as adsorption, ion exchange etc. The coefficients of determination as obtained from the plots were found to be very close to unity for all initial dye concentrations.

Table-7

\begin{tabular}{|l|l|l|}
\hline $\mathbf{C o} \mathbf{~ m g / L}$ & $\mathbf{K}_{\mathbf{2}}$ & $\mathbf{R}^{\mathbf{2}}$ \\
\hline 0.799 & 0.178 & 0.994 \\
\hline 79.99 & 0.12 & 0.99 \\
\hline
\end{tabular}

The plots of $\log (q e-q t)$ vs. $t$ indicated the non applicability of the pseudo first order model. On the basis of the values of slope and $\mathrm{R}^{2}$ values it was concluded that this model is not useful to explain the kinetics of sorption of $[\mathrm{MB}]^{+}$using S-IV. The plots of t/qt vs. $t$ for initial concentrations $0.799,7.99,39.99$ and 79.99 $\mathrm{mg} /$ Ltr. gave straight line plots. 

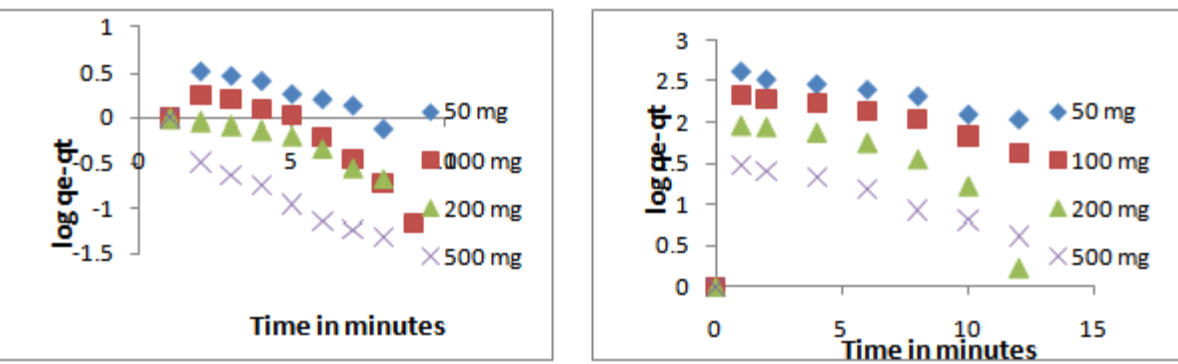

Fig. 9: Lagergren plots for initial concentrations $\mathrm{Co}=0.799 \mathrm{mg} / \mathrm{Ltr}$. $\mathrm{Co}=79.9 \mathrm{mg} / \mathrm{Ltr}$.

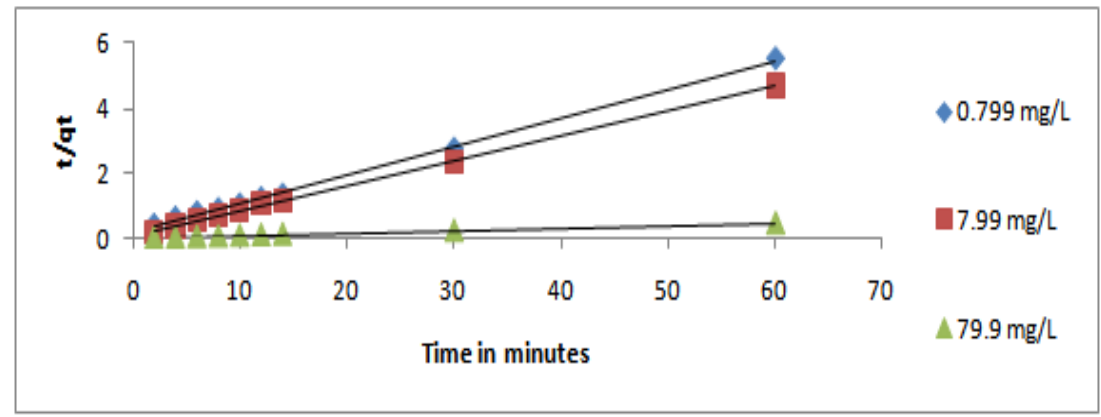

Fig.10 multiple plots of $t / q t$ vs $T$ for S-IV

VII. Intraparticle diffusion model Table-8

\begin{tabular}{|l|l|l|}
\hline Initial concentration $\mathbf{~ m g / L t r . ~}$ & Kp mg/Ltr. & Intercept \\
\hline 0.799 & 0.652 & 7.95 \\
\hline 79.99 & 2.43 & 113.6 \\
\hline
\end{tabular}

Commonly mechanism involved in the sorption process is the intraparticle diffusion model. Plots of $\mathrm{q}$ vs. $t^{1 / 2}$ fig. 11 gives an idea of the mechanism involved. In a batch reactor pore distribution and intraparticle diffusion are often the rate determining steps. The plots of $q$ vs. $t^{1 / 2}$ show separate regions. The initial parts of the curve can be attributed to mass transfer effects. While the next linear portion indicates intraparticle or pore diffusion. The initial portion is also indicative of surface sorption and the boundary layer effect. Slope of the $2^{\text {nd }}$ linear portion of the plot is defined as the intraparticle diffusion parameters $\mathrm{Kp}$ or Kid while the intercept of the plots gives an idea about the boundary layer. In our work the values of the intercepts are found to be concentration dependent for the adsorption of $[\mathrm{MB}]+$ cation onto sorbents S-IV. Intercept of the plots q vs. $t^{1 / 2}$ for $0.799 \mathrm{mg} / \mathrm{L}$ and $79.9 \mathrm{mg} / \mathrm{L}$ are found to be $7.95,113.62$ for S-IV. These results clearly indicate that boundary layer effect increases with the initial concentration of the dye. As observed in the graph we can see an initial curved portion which can be attributed to liquid -film mass transfer, while the latter portion reveals linearity which is characteristic of sorption processes where intraparticle diffusion is controlling step such phenomenon have been observed for the adsorption of the dye on activated carbon.

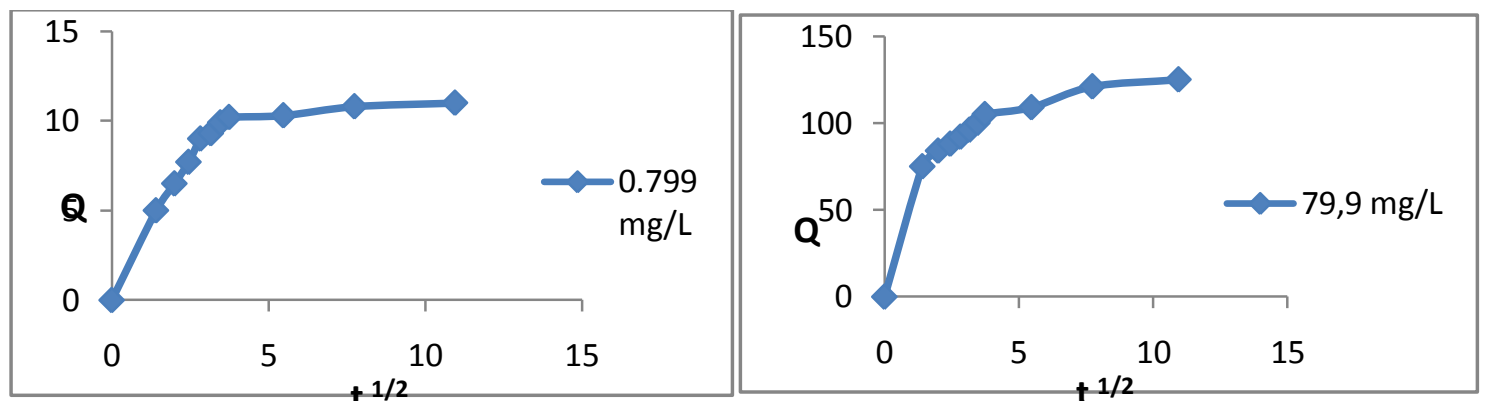

Fig.11 A) Plots of Q vs. $\mathrm{t}^{1 / 2}$ for S-III, $0.799 \mathrm{mg} / \mathrm{L}, 79.9 \mathrm{mg} / \mathrm{L}$ 


\section{Conclusions}

- Removal of $[\mathrm{MB}]^{+}$on S-IV is a time dependent process, equillibrium is attained within 30 minutes.

- The adsorption is initially very rapid and the rate then slows down. The adsorbent dose has a substantial effect on the percentage of adsorption, as the adsorbent dose is increased from $50 \mathrm{mg} / 100 \mathrm{ml}$ to $500 \mathrm{mg} / 100 \mathrm{ml}$ the initial adsorption increases from $70 \%$ to $79.87 \%$.

- The adsorption capacity is found to increase up to $\mathrm{pH} 4$ and afterwards decreases. At higher $\mathrm{pH}$ the increased $\mathrm{OH}^{-}$concentration in the solution hold back the $[\mathrm{MB}]+$ in solution and hence a reduction in $\%$ sorption and sorption capacity.

- S- IV displayed plots with $\mathrm{Kp}$ values 0.652 and $2.43 \mathrm{mg} / \mathrm{Ltr}$. for $\mathrm{Co}=0.799 \mathrm{mg} / \mathrm{Ltr}$. and $79.9 \mathrm{mg} / \mathrm{Ltr}$. These values of $\mathrm{Kp}$ indicate that the structures of S-IV are not micro porous.

- With the increase in temperature the sorption capacities also increase. The increase in sorption capacities with temperature indicates increasing mobility of the $[\mathrm{MB}]^{+}$ions.

- The increase in the value of $\mathrm{x} / \mathrm{m}$ with temperature also indicates the sorption process to be endothermic.

- For an initial concentration $\mathrm{Co}=0.799 \mathrm{mg} / \mathrm{Ltr}$. and $79.9 \mathrm{mg} / \mathrm{Ltr}$.., the $\mathrm{KD}$ values vary between 1.745 to 2.665 and 3.22 to 6.59 respectively for S-IV over the temperature range studied.

- The value of KD is found to increase with rise in temperature.

- The $\Delta \mathrm{G}$ values at the different temperature studied have negative values indicating spontaneity of the process for S-IV

- Kinetic modeling suggests that the process follows the pseudo second order kinetics. The values of Kf range between and $5.08-8.68$ and the values of $1 / \mathrm{n}$ are less than unity for indicating good intensity of adsorption for temperature $15,25,35$ and $45^{\circ} \mathrm{C}$.

- The intraparticle diffusion studies indicate that it is not the rate determining step and adsorption may be governed by mass transfer as well.

- The adsorption obeys the Langmuir isotherm. The Hall separation factor values indicate favorable adsorption.

\section{Acknowledgement}

I Dr. A. A. Kale sincerely thankful to Dr. Rajashree Kashalkar Head, department of chemistry of S.P.College Pune. Principal, Dr.A.S. Burungale Secretary, Rayat Shikshan Sanstha Satara and Principal, Dr. Mohan Rajmane S.G.M.College, Karad for motivation to my research.

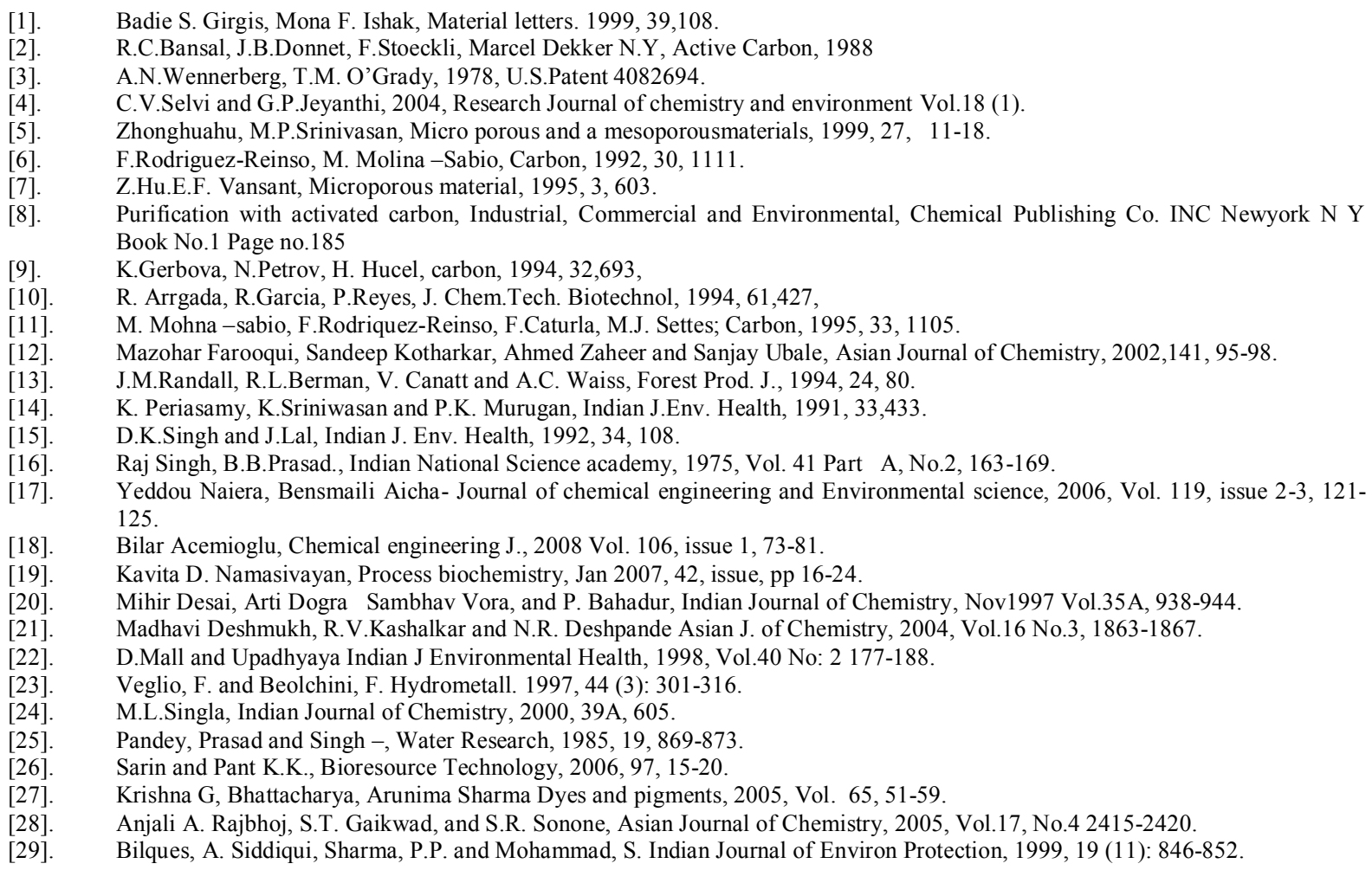

